\title{
A FORMAÇÃO DO EDUCADOR A PARTIR DA COMPLEXIDADE E DA TRANSDISCIPLINARIDADE
}

\author{
The teaching formation process from the \\ complexity and transdisciplinarity
}

Maria Cândida Moraes ${ }^{1}$

\section{Resumo}

Com este artigo, a autora examina a formação docente a partir das implicações epistemo-metodológicas da complexidade e da transdisciplinaridade, tendo em vista alguns pressupostos do Pensamento Complexo de Edgar Morin, da teoria tripolar de formação de Gastón Pineau e do Pensamento Eco-Sistêmico de M. C. Moraes. Como princípio regulador do pensamento e da ação, a complexidade exige que repensemos a formação docente a partir de um processo de formação integral de natureza transdisciplinar e que inclui os três pólos de formação: autoformação, heteroformação e ecoformação, reconhecendo a importância de sua dinâmica integrada para a vida pessoal e profissional docente. Destaca a necessidade de se dar atenção especial aos processos de autoformação, alegando que esta dimensão tem sido a menos trabalhada e considerando-a uma das mais importantes para a conquista de sua autonomia profissional, pessoal e existencial do professor. Alega que nela está também contido um processo de antropogênese que transita entre a auto e a ontoformação, onde o Eu psicológico, o Eu social e o Eu docente estão todos imbricados e influenciando, simultaneamente, tanto o SER como o FAZER docente. É, portanto, a partir da dinâmica operacional entre esses três pólos constitutivos da ação docente que emerge a complexidade subjacente à ação formadora e que se revela tanto no nível da ação de um sujeito que é multidimensional, como também no técnico-pedagógico ou no sociocultural, aspectos estes que representam a totalidade constitutiva de um sistema de formação docente, a partir da complexidade. Reconhece que todo processo formativo implica, portanto, uma dinâmica auto, hetero e ecoformadora de natureza complexa, aberta, fundada na solidariedade, no questionamento constante e nas reflexões desenvolvidas e apoiadas pelos recursos técnico-tecnológicos disponíveis. Esta visão desvela processos que envolvem incerteza, emergência, mudança, recursividade e transformação e que requerem do profissional docente um maior compromisso e responsabilidade com a educação como decorrência natural de sua consciência transdisciplinar em processo de transformação.

Palavras-chave: Complexidade; Transdisciplinaridade; Autoformação; Heteroformação; Ecoformação.

1 Doutora em Educação pela PUCSP, Professora do Programa de Pós-Graduação em Educação (Currículo) da PUCSP e da Universidade Católica de Brasília - UCB.

e-mail: mcmoraes@terra.com.br 


\section{Abstract}

The author examines teacher development based upon the epistemomethodological implications of the theories of complexity and transdisciplinarity, taking into consideration several of the premises of Complex Thought by Edgar Morin, of Tripolar Education Theory by Gastón Pineau and of Eco-Systemic Thought by M.C. Moraes. As the regulating principle of thought and action, the notion of complexity requires us to rethink teacher development starting with an integral and transdisciplinary process including three poles of development: selfformation, heteroformation and eco-formation, recognizing the importance of their integrated dynamics within the teacher's personal and professional life. Noteworthy is the need to pay special attention to the self-formation processes, this dimension having been almost overlooked despite its being considered one of the most important dimensions for the teacher's achievement of professional, personal and existential autonomy. It is alleged that this dimension also involves a process of antropogenese that transits between self and onto-formation, where the psychological I, the social I, and the teacher I are all working together, simultaneously influencing not only the BEING a teacher but the ACTION of teaching. Therefore, it is from the operational dynamic between these three poles, which constitute the act of teaching, that the complexity underlying the act of development emerges and is revealed not only at the level of action of a multidimensional subject but also at the technical-pedagogical and socio-cultural levels as well, these aspects representing the totality that constitutes the system of teacher development from complexity.Therefore, it is recognized that every development process implies a self, hetero and eco dynamic that is complex, open, and founded on solidarity, on continuous inquiry, and on the reflections developed and supported by the available technical and technological resources. This point of view reveals processes that involve uncertainty, emergency, change, recursivity and transformation, and which require greater commitment and responsibility from the teacher towards education as a natural outcome of his/ her transdiciplinary consciousness in the transformation process.

Keywords: Complexity; Transdisciplinary; Self; Hetero and eco-education.

\section{Introdução}

Como fica a questão da formação docente a partir dos aspectos ontológicos, epistemológicos e metodológicos da complexidade? Será que o professor tem consciência das implicações de sua maneira de observar e compreender a realidade complexa e as conseqüências metodológicas em sua prática pedagógica? Acreditamos que a grande maioria dos educadores não tem clareza a respeito da existência de relações lógicas entre as várias dimensões caracterizadoras dos diversos paradigmas científicos. 
Assim, como trabalhar a formação docente a partir do Pensamento Eco-Sistêmico que tem a complexidade e a transdisciplinaridade como uns dos seus pressupostos principais? Na realidade, não estamos acostumados a pensar de maneira sistêmico-ecológica, a partir de um enfoque orgânico, modular, estrutural, dialético, inter e transdisciplinar, onde as partes afetam a dinâmica do todo e os processos tendem à diferenciação e não à homogeneização a partir de suas relações com os demais elementos da rede. Desta forma, pensar a formação, a partir desses referenciais, requer uma mudança profunda de natureza ontológica, epistemológica e metodológica, caso contrário, continuaremos fragmentando o ser humano, o conhecimento e a realidade educacional e não dando conta dos reducionismos que ainda prevalecem nos processos formadores dos profissionais da educação.

Sabemos que o problema da formação docente passa necessariamente por uma discussão profunda e abrangente que perpassa vários aspectos de extrema importância e que estão relacionados à necessidade de uma revisão significativa nas bases constitutivas dos sistemas educativos, como condição efetiva para um melhor equacionamento da problemática que afeta a formação docente. Passa, portanto, não apenas pelos aspectos pedagógicos, mas também pelas condições de trabalho, de emprego e pela deterioração salarial entre tantas outras variáveis importantes. O Pensamento Eco-Sistêmico, fundamentado na complexidade, exige o repensar a docência de um modo mais articulado, integrado e competente.

Para tanto, necessitamos também refletir sobre o enfoque tradicional que subsidia os trabalhos de formação docente, que com todos os seus vícios e estratégias, reproduzem um modelo de ensino de natureza tradicional. Este novo pensar destaca a importância de se trabalhar, articulada e simultaneamente, os fundamentos, processos e estratégias de formação, reconhecendo também que todos esses aspectos precisam se pensados conjuntamente e de maneira articulada. Entretanto, o foco desta etapa do nosso trabalho deverá estar prioritariamente direcionado para os aspectos relacionados às implicações da complexidade e da transdisciplinaridade nos processos de formação e o que tudo isto representa ou poderá vir a representar num futuro próximo.

Concordamos com Rosa M. Torres (2002) ao comentar que a maioria das críticas aos processos de formação docente não tem nenhuma novidade, o mesmo acontecendo com o sistema escolar, cujo foco tem sido geralmente centrado em aspectos muito superficiais. Critica-se a sua desatualização teórica e prática, o excesso de disciplinas, a formação conteudista dos profissionais da educação, as dificuldades e incompetências para se tratar questões relacionadas com as tecnologias digitais sem, contudo, se pensar na problemática educacional como um todo. 
Apesar das inúmeras denúncias feitas ao longo da década de 90, na realidade, os problemas educacionais continuam sendo trabalhados de modo fragmentado, desarticulado, de maneira isolada. Tenta-se introduzir pequenas melhorias colocando-se um remendo aqui, outro ali, priorizando este ou aquele tema mais "modernoso" em seminários, sem, entretanto, enfrentar o mal pela raiz. Uma coisa é o discurso aparentemente atualizado e bem fundamentado. Outra coisa é a situação que emerge na prática, as políticas adotadas e verticalmente impostas, desvinculadas dos verdadeiros compromissos com mudanças mais profundas requeridas pelas mais diferentes esferas educacionais.

Segundo Torres (2002), o que não vem funcionado no Brasil e na América Latina em geral não é a formação docente propriamente dita, mas os modelos de formação como um todo, seja a formação inicial ou em serviço. Entre outros aspectos, tais modelos têm primado por uma ignorância explícita, um grande desestímulo em relação aos aspectos apresentados anteriormente, que ignoram o conhecimento e as experiências acumuladas, ao longo da vida, pelos profissionais de educação. Alega também a falta de conhecimento a respeito das reais condições do professorado, no que se refere às variáveis relacionadas à motivação, às inquietudes, ao tempo e aos recursos disponíveis.

Em sua maioria, as políticas e estratégias adotadas partem de uma concepção de tratamento homogêneo no que se refere ao professorado em geral, sem, contudo, atentar para as necessidades e peculiaridades dos diferentes tipos de professores envolvidos, bem como para suas necessidades mais prementes. É uma sistemática de planejamento e implementação de políticas e práticas educacionais nas quais não são trabalhados os processos naturais de diferenciação que acontecem em cada profissional no decorrer de sua prática. $\mathrm{Na}$ realidade, privilegia-se muito mais a homogeneização, oferecendo um tratamento igual para todos, sem pensar nos processos de diferenciação de cada um. O problema é que, muitas vezes, elaboram-se tais propostas como se todos aprendessem da mesma maneira, como se a aprendizagem do adulto fosse similar à do jovem ou da criança.

Desta forma, como desenvolver um processo de formação voltado para a autonomia profissional e para um protagonismo docente mais competente, se os processos vivenciados continuam sendo castradores, alienantes, desestimuladores e desvinculados da realidade educacional em seus vários aspectos? Será que a complexidade e a transdisciplinaridade podem mesmo colaborar para a construção de novas práticas docentes? Mas, em que aspectos? E como?

A resposta, ou respostas, a estas questões requer novas posturas nos seus mais diversos níveis. Desde o nível de políticas de Estado, passando também pelo repensar das organizações responsáveis pela formação docente até se chegar à escola. A situação implica um repensar global dos programas, 
projetos e estratégias de formação, pois uma melhor qualidade na formação docente não acontece modernizando-se as instalações com novos equipamentos ou priorizando esta ou aquela solução tecnológica. Nem se retocando o velho currículo com um leve "botox", melhorando discursos, aumentando os anos de estudo ou adicionando esta ou aquela nova disciplina curricular. É preciso um esforço coordenado, sistemático e simultâneo que articule vários aspectos. Dentre eles, precisamos de uma proposta competente de reforma curricular da formação docente que leve em consideração o tempo e a disponibilidade dos interessados, a possibilidade de um diálogo mais competente entre Estado, sociedade e as organizações docentes, bem como novos referenciais teóricos relacionados aos novos paradigmas da ciência.

\section{Perfil docente}

Mas, antes, precisamos saber qual é o perfil deste docente idealizado e quais são os principais desafios a serem enfrentados para sua concretização. Será mesmo possível falar de um perfil ideal a partir dos fundamentos teóricos professados? Não é meio estranho se pensar em um padrão idealizado como se não existissem processos de diferenciação que vão acontecendo no cotidiano da vida? Certamente, não estamos falando de padrões ou modelos, mas em características docentes que, de certa forma, deveriam predominar.

Há tempos na Academia vem se discutindo a respeito deste novo perfil ideal que está sendo exigido pela atual conjuntura política, econômico, social e educacional. Na realidade, em vários programas e projetos governamentais encontramos este perfil muito bem definido, embora saibamos que, com raras exceções, tem-se ficado muito mais no discurso do que na prática. Existiria, hoje, espaço para aquele professor enciclopédico, que "conhece tudo", que transmite "conhecimento" de cima para baixo, sem se preocupar com o que está acontecendo com os seus alunos, com suas escolas, com sua comunidade ou com o seu país? Com certeza, não!

Mais do que ontem, tendo em vista o potencial das tecnologias digitais e seus ambientes colaborativos, precisamos de um profissional de educação capaz de elaborar um projeto coletivamente significativo e relevante, e que nele se desenvolva bem, seja participando do projeto pedagógico da escola ou dos processos de aprendizagem de seus alunos. Hoje, se necessita mais de um professor que tenha, além de uma prática reflexiva e crítica, também uma escuta sensível e uma consciência mais elaborada; um sujeito mais atento aos processos auto-organizadores de seus alunos, capaz de olhar para eles e identificar suas necessidades básicas, de intuir suas angústias e de converter tudo isto em subsídios para as atividades de ensino e aprendizagem (BARBIER, 
2004). Aquele professor controlador, cobrador, insensível, enciclopédico, incapaz de uma interação compreensiva e colaborativa já não faz muito sentido. Na realidade, nossas escolas necessitam de professores capazes de organizarem ambientes agradáveis e efetivos de aprendizagem, ambientes prazerosos e implicativos, onde os alunos sintam-se acolhidos, compreendidos e nutridos no seu sentido mais amplo.

Para tanto, é preciso também reconhecer que este docente estará atuando em um ambiente de aprendizagem, seja ele virtual ou presencial, que precisa ser compreendido como um ecossistema, um local de interdependências e emergências, de processos colaborativos inter-relacionados e nutridores, um local onde todos devam colaborar para manutenção e evolução do sistema como um todo. Desta forma, necessitamos daquele docente capaz de participar, sempre que necessário, de trabalhos em grupo, com capacidade para refletir criticamente sobre sua prática e de levar os seus alunos a refletirem sobre suas ações, sobre os seus erros e acertos. Um docente sensível e capaz de perceber os momentos das bifurcações, das emergências, os momentos em que algo precisa ser mudado, refletido ou reconstruído na prática cotidiana.

Enfim, é um professor capaz de tomar decisões adequadas, oportunas e criativas, que saiba pesquisar e encontrar, em sua prática, as soluções para os problemas. Alguém que seja verdadeiramente capaz de resolvê-los, que saiba optar, com competência e discernimento, diante dos dilemas. Um sujeito capaz de reconhecer sua tarefa criadora, não apenas atualizadora, mas, sobretudo, transformadora das novas gerações, tendo em vista nosso mundo complexo e mutante, tão cheio de inquietudes, saltos e sobressaltos. Como aprender a ser um docente criativo, questionador e inovador, capaz de responder a tantos desafios? Sabemos que as respostas não são fáceis e nem podem ser superficiais, tendo em vista a complexidade e a abrangência de sua tarefa formativa, formadora e, potencialmente, transformadora. Mas, independente das dificuldades apresentadas, precisamos avançar neste sentido e colaborar para que a luz se faça presente, dentro das limitações pessoais e institucionais que caracterizam as zonas de sombras que, hoje, tanto afetam a educação.

É esta capacidade autoquestionadora, auto-reflexiva e autotransformadora e, ao mesmo tempo, colaborativa, que o levará ao exercício de uma aprendizagem autêntica, segundo Pedro Demo (1999). Uma aprendizagem baseada num esforço reconstrutivo, no qual ele reescreve sua própria história, mas, ao fazê-la, parte de sua relação consigo mesmo e com o outro, com o contexto social no qual está inserido. Aprender bem, para Demo (1999), significa saber reconstruir o conhecimento com qualidade formal e política, o que o leva à sua emancipação e à conquista de sua autonomia pessoal e profissional. Ainda para o autor, aprende-se bem com um professor que sabe aprender bem, ou seja, com aquele que é capaz de construir, desconstruir e reconstruir o conhecimento, sempre que necessário. 
Além de aprendiz e inovador permanente, construtor e reconstrutor do conhecimento e de sua própria aprendizagem, um bom docente é aquele capaz de ajudar seus alunos a desenvolver habilidades e competências consideradas fundamentais à sua sobrevivência e transcendência. Entre essas capacidades está a de ajudar o aprendiz a olhar para dentro de si mesmo, para dentro de seu próprio ser, para que possa reconhecer-se como pessoa, descobrir seus talentos e competências, sua criatividade, sua sensibilidade e sua flexibilidade estrutural em relação ao conhecimento; perceber sua capacidade de antecipação e de adaptação às situações emergentes caracterizadoras de nossa realidade mutante.

O perfil desejado é, portanto, de um docente capaz de discernimento, de atitude crítica diante dos problemas; é um sujeito pesquisador, interdisciplinar e/ou transdisciplinar em suas atitudes, pensamentos e práticas. Um sujeito observador que percebe o momento adequado da bifurcação e da mudança, capaz de enfrentar um novo desafio ao ter que iniciar uma nova disciplina ou uma nova estratégia pedagógica inspirada nos princípios da complexidade, da interdisciplinaridade e da transdisciplinaridade. Além de ser um professor humanamente sábio, é também um sujeito tecnologicamente fluente e capacitado na utilização crítica e competente das tecnologias digitais; um sujeito capaz de ensinar e de aprender a compartilhar com seus alunos, para que possa desenvolver um novo fazer e um novo saber mais competente, atualizado, construtivo, reflexivo, criativo e ético. A ética deverá estar sempre presente em todas as suas ações, atitudes e decisões tomadas.

Muito poderia ser dito sobre o perfil deste novo profissional que está sendo requerido neste início de milênio. Entretanto, o foco deste trabalho não é apenas este. É, sobretudo, identificar e analisar o que a complexidade e a transdisciplinaridade podem colaborar para as transformações necessárias em relação a este novo perfil docente.

\section{Complexidade}

De cara, é importante reconhecer e observar que a complexidade exige que a formação docente seja pensada como um todo, como um continuum, de modo integrado e articulado em relação aos diferentes processos e dimensões envolvidas. Esta compreensão está de acordo com o princípio sistêmico-organizacional que explica que um sistema é uma unidade global organizada por inter-relações (MORIN, 1997). Portanto, pensar de maneira complexa é ver o objeto relacionalmente, pois não podemos fragmentar o que é complexo e relacional. Nas palavras de Morin (1999), "tudo que isola um objeto, destrói sua realidade". Assim, para que possamos compreender o todo, 
constituído, por exemplo, pelo sistema de formação docente, é preciso conhecer as relações todo/partes. Assim, este princípio liga e religa o conhecimento das partes com o todo e vice-versa. Isto significa que as mudanças que estarão sendo sugeridas não se referem somente à formação continuada, mas também aos processos de formação inicial, tornando-os mais adequados e competentes às demandas atuais. Ambos os tipos de formação são partes constitutivas de uma totalidade integrada que constitui um sistema de formação docente.

Como princípio regulador do pensamento e da ação, como maneira de pensar e compreender a realidade, a complexidade exige que pensemos a formação docente a partir de um processo de formação integral (TORRE; BARRIOS, 2002; MORAES; TORRE, 2004) e de uma formação de natureza tripolar, como quer Pineau e Patrick (2005). Como processo de formação integral, Torre e Barrios (2002) recomenda um modelo ${ }^{2}$ de ensino que seja holístico em suas metas, integrador em suas propostas, adaptado aos diferentes contextos, polivalente em suas estratégias e sistemáticas de avaliação. "Um modelo que vai além do conhecimento, pois educação não é ato transmissivo, mas criativo, construtor e transformador" (TORRE; BARRIOS, 2002, p. 77).

Em sua proposta de formação integral, Torre e Barrios (2002, p. 78):

Concebe a formação como mudança e tem como referentes ou pressupostos teóricos a mudança, como organizadora conceitual da realidade e princípio de construção do conhecimento; a consciência como construto que faz presente o que estava ausente, visível o invisível, possível o imaginário, a confrontação ou tensão inferencial que está na origem de toda mudança; a complexidade como qualidade inerente à ação, ao pensamento e sentimento humanos; a comunicação como veículo de expressão e realização [...] É a comunicação, em seu sentido mais amplo, que nos humaniza.

Ampliando um pouco mais esta construção teórica, reconhecemos que a mudança é um dos pressupostos epistemológicos fundamentais de todo processo inovador/transformador a partir dos fundamentos teóricos explicitados anteriormente. Ela é um componente importante de todo e qualquer processo formativo, autoformador e transformador. Ontologicamente falando, é algo intrínseco à própria natureza do ser, da matéria e da vida. Como elemento

2 É importante observar que, como educadores fundamentados no pensamento complexo, temos que repensar o uso da palavra modelo. Quando utilizada, sabemos que ela apresenta uma representação semântico/descritiva ou causal/explicativa, mas que, na realidade, não deixa de ser uma abstração esteriotipada da realidade, uma maneira reducionista de refletir uma realidade de natureza complexa. Na maioria das vezes, modelos não passam de esquemas reveladores de certa parcialidade, que expressa certo empobrecimento relacional de um fenômeno verdadeiramente complexo. Tentar aprisionar em esquemas uma realidade dinâmica, complexa, mutante e incerta como é a realidade educacional, hoje, já não faz muito sentido. 
constitutivo e organizador da matéria, aquilo que tem a energia como princípio causativo (SHELDRAKE; ABRAHAM; MAKENNA, 1994), a mudança também se encontra presente em todos os níveis e domínios da realidade e, conseqüentemente, apresenta-se também nos processos de construção do conhecimento e na aprendizagem.

Para Torre e Barrios (2002), a mudança é a testemunha silenciosa de qualquer processo formativo. É ela que nos ajuda a perceber que o processo educativo/formativo alcançou a finalidade que lhe corresponde, bem como nos ajuda a compreender a importância dos nossos erros como etapas de um processo de aprendizagem mais amplo e abrangente. Biologicamente falando, é possível perceber que "tudo que forma, na realidade, se transforma" dentro de cada um de nós, em função da bio-psico-sociogênese do conhecimento humano. Conseqüentemente, conhecimento e aprendizagem implicam processos auto-organizadores, auto-reguladores e autotransformadores que envolvem uma cooperação global que acontece nas diferentes dimensões presentes na corporeidade humana. É esta consciência mais ampla a respeito dos processos de mudança que nos ajuda a construir e a reconstruir nossa autonomia na prática cotidiana dos nossos afazeres docentes. A mudança está, portanto, na raiz dos processos autopoiéticos, formadores e autotransformadores que envolvem a complexidade humana.

Acreditamos que a complexidade como fator constitutivo da realidade e da vida é, portanto, inerente à ação do sujeito, ao seu pensamento e ao objeto com que trabalha. Enfim, é inerente à dinâmica da vida. Sendo um fator constitutivo da vida, isto significa que a complexidade, como expressão de uma tessitura comum, é o que possibilita a vida e favorece o desenvolvimento da inteligência, do pensamento e a evolução dos sistemas vivos. Como fator constitutivo da vida, significa que ela rege os acontecimentos, as ações, os eventos e os processos e, desta forma, ontológica e epistemologicamente falando, ela não permite separar ser/realidade, sujeito/objeto, educador e educando, objetividade/subjetividade, sujeito/cultura e sociedade, bem como retirar do sujeito docente/discente suas qualidades mais sensíveis. É a complexidade que nos ajuda a melhor compreender e explicar a realidade educacional, esclarecendo-nos que esta não é apenas feita de racionalidade e de fragmentação, mas também de processos intuitivos, emocionais, imaginativos e sensíveis. Isto porque, nós, seres humanos, somos também feitos de poesia e de prosa, de emoção, de sentimento, de intuição e de razão e tudo isto, orgânica e estruturalmente, articulado em nossa corporeidade.

É ela que nos informa que a realidade educacional não é previsível, ordenada e determinada, não podendo ser aprisionada por este ou aquele modelo de ciência, nem por este ou aquele pensamento reducionista, único e verdadeiro. O mesmo acontece com os processos formativos, pois grande 
parte é construída a partir de situações conflitivas, desordenadas, indeterminadas, muitas vezes, absolutamente caóticas. Isto porque o caos é um fenômeno que se apresenta em qualquer dimensão da realidade e desta forma, também nos processos educacionais, provocando situações imprevisíveis, indeterminadas, novas e surpreendentes emergências e convergências. Isto significa que, em educação, também devemos aceitar a presença do incerto, da desordem, do acaso, das inovações, dos imprevistos que trazem consigo o movimento e a mudança como elementos inerentes às situações da vida e que, muitas vezes, apresentam-se nas situações formativas, formadoras e, na realidade, autotransformadoras.

A partir desta compreensão, precisamos deixar de temer a presença desses fatores em nossas vidas e em nossas práticas pedagógicas. O importante é também aprender a trabalhar em situações difíceis, caóticas e incertas, tirando delas o melhor proveito, assim como reconhecer e aprender a trabalhar as emergências e as bifurcações inesperadas.

Mas, como docentes, não fomos formados para trabalhar as emergências que acontecem nos ambientes de aprendizagem e, conseqüentemente, temos dificuldades em reconhecê-las e em conviver com elas. Nossa formação docente foi toda pautada por uma causalidade linear, do tipo causa-efeito, por uma linearidade docente do tipo estímulo-resposta, por processos do tipo início-meio e fim, esquecendo que "os efeitos retroagem sobre as causas, realimentado-as ou modificando-as". Este é o enunciado de um dos princípios fundamentais da complexidade, o princípio recursivo, que tem na causalidade circular, de natureza retroativa ou recursiva, um dos seus operadores epistemológicos principais. A partir deste princípio, os desvios, os erros e as emergências passam a dialogar e a alimentar novamente o sistema e a evoluir com ele (MORIN, 1997).

Um outro aspecto interessante é perceber que esta mesma causalidade complexa nos permite ver de outra maneira os fenômenos complexos, cuja dinâmica é processual, inacabada e transitória, bem como as interações sujeito/ objeto, teoria/prática. Nestas, a circularidade existente entre ambas rompe com a causalidade linear, pois a ação de uma retroage sobre a outra, realimentando-a ou modificando-a. Uma poliniza a outra. Uma está sempre fertilizando ou fertilizada pela outra. Assim, melhorando a nossa prática, esta melhoria retroagirá informacionalmente sobre os conceitos trabalhados e iluminará a construção teórica desenvolvida. Por sua vez, estando informacionalmente mais enriquecido, este corpo conceitual reconstruído retroagirá novamente sobre a prática, modificando-a. E tudo isto indefinidamente.

Assim, para aprender a trabalhar com o erro, com as emergências e com a causalidade circular, é preciso humildade intelectual e abertura de nossas gaiolas 
epistemológicas e disciplinares, para que o conhecimento antigo possa liberar espaço para que o novo possa ser construído e reconstruído, movimentando, assim, a espiral da aprendizagem e nutrindo a dinâmica da vida.

Muitas vezes, um erro, uma emergência ou uma bifurcação inesperada surge no caminho e nos obriga a optar por um outro diferente do anteriormente planejado. Mais tarde, descobrimos o quanto este momento decisivo foi rico e importante para o desdobramento de outros processos não previstos, mas que também foram muito significativos em seus vários aspectos. Desta forma, tanto o acaso como as bifurcações são componentes importantes e essenciais na história evolutiva dos sistemas vivos, já nos dizia Prigogine (1986). Por meio de uma bifurcação qualquer na trajetória traçada, o sistema muda o rumo evolutivo da história, reconquistando, posteriormente, novas situações de equilíbrio, de ordem, de desenvolvimento e evolução.

Isto nos revela que a complexidade e o caos trazem também consigo mecanismos intrínsecos de auto-regulação, de intercâmbios e trocas, pois neles a ordem, a desordem e o acaso se associam em prol da evolução orgânica do sistema. Desta forma, em um processo de formação, este olhar complexo é de extrema importância, pois rompe com a linearidade causa-efeito, com o determinismo, com a fragmentação e com a passividade, aspectos tão presentes nos sistemas formadores mais tradicionais, de natureza fechada. Com isto, sabemos que já não é possível se pensar na formação docente como um processo de treinamento qualquer em termos de habilidades e destrezas, nem no manejo de métodos e técnicas que privilegiem a linearidade, a passividade, a aceleração, bem como a tomada de decisões verticais, autoritárias e prepotentes.

Um outro princípio metodológico importante da complexidade é o princípio ecológico da ação que nos informa que nossas ações, freqüentemente, escapam às nossas primeiras intenções e produzem efeitos inesperados e, muitas vezes, imprevisíveis e opostos ao que foi anteriormente planejado. Uma vez desencadeada, qualquer ação passa a fazer parte de um jogo de interações do qual a aleatoriedade, a incerteza e a imprevisibilidade do ambiente natural ou sociocultural estão sempre presentes. Será possível programá-las em uma estrutura de planejamento muito rígida? A partir dos fundamentos epistemo-metodológicos da complexidade, será mesmo possível programar a ação, a descoberta, a aprendizagem e o conhecimento?

Certamente, não estamos fazendo apologia da improvisação, mas alertando que a complexidade traz consigo a imprevisibilidade, a emergência e a não-linearidade, o que exige estruturas de pensamento e de planejamento mais dinâmicas e flexíveis. E mais, não podemos ter uma visão estável da realidade, do mundo e da vida, mas uma concepção processual, dinâmica, ativa, onde tudo é inacabado e transitório, sempre em processo de vir-a-ser. 


\section{Complexidade e transdisciplinaridade}

É esta mesma complexidade inerente ao sujeito e ao objeto, em sua dimensão epistemo-metodológica, que é também considerada um dos três eixos constitutivos da transdisciplinaridade. Da mesma forma, a complexidade também se encontra presente na docência transdisciplinar, tanto no que se refere aos aspectos ontológicos e epistemológicos como nos metodológicos e estratégicos. Isto significa que ela participa com todos os seus princípios metodológicos da ação formadora transdisciplinar e é também nutrido pelas outras duas dimensões, como veremos mais adiante.

Assim, a partir da transdisciplinaridade e da complexidade constitutiva da realidade, um processo de formação docente precisa também ser trabalhado a partir dos três eixos propostos por Nicolescu (2002). Ou seja, metodologicamente falando, deve-se atuar levando em conta os níveis de realidade, o terceiro incluído e a complexidade na relação sujeito/objeto. Mas, o que é que isto significa? Isto nos indica que uma docência epistemometodologicamente transdisciplinar é construída mediante articulação competente desses três pólos. Para Pineau e Patrick (2005, p. 131) isto implica uma teoria tripolar de formação que inclui os três níveis de análises autoformação, heteroformação e ecoformação -, e um triplo nível de consciência e de percepção da realidade. O triplo nível de consciência corresponde ao que acontece em cada nível de formação explicitado e o triplo nível de realidade inclui a percepção e compreensão de sua multidimensionalidade e multirreferencialidade (ARDORNO, 1998).

Foi explorando a metodologia das histórias de vida e as diversas formulações que os sujeitos dão aos seus trajetos de formação que Pineau formulou a teoria dos três movimentos que interferem na formação-personalização, socialização e ecologização - o que o levou a criar os conceitos de auto, hetero e ecoformação. (SOMMERMAN, 2003, p. 59).

Para Pineau (2006), a utilização desses prefixos nos processos de formação inscreve-se nesse movimento transdisciplinar de tentativa de tratamento de sua multicausalidade. Esta concepção de formação tripolar pode ser assim representada: 
autoformação

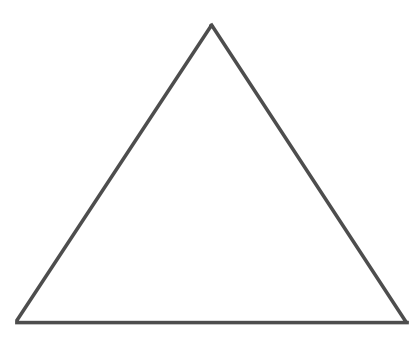

eco-formação heteroformação

Para Sommerman (2003, p. 59), citando Pineau:

O termo autoformação apareceu antes dos outros dois, catalisando as pesquisas sobre a autonomização dos atores pela apropriação de se poder de formação. Personalizando, individualizando e subjetivando a formação. A autoformação é a apropriação do sujeito de sua própria formação. [...] o termo heteroformação designa o pólo social de formação, os outros que se apropriam da ação educativo-formativa da pessoa. O termo ecoformação é a dimensão formativa do meio ambiente material, que é mais discreta e silenciosa do que as outras.

Segundo Pineau (2006), nos processos formativos, nenhum dos pólos deve ser priorizado em detrimento do outro. Mas sua dinâmica tripolar, de natureza complexa, é que deve ser estudada ao longo da vida do formador. Há períodos em que uma dimensão prevalece sobre a outra. Isto depende do momento existencial de cada um, das condições em que se encontra e das oportunidades oferecidas.

Neste trabalho, pretendemos dar uma atenção especial à autoformação, como sendo a mais esquecida em relação às outras, pois ela envolve a dimensão da evolução da consciência humana. A autoformação implica a tomada das rédeas da vida nas próprias mãos, seja da vida profissional como pessoal, bem como a conquista de sua autonomia existencial, o tornar-se sujeito. É aqui que Pineau, citado por Sommerman (2003), adverte-nos que esta dimensão implica: tornar-se objeto de formação de si mesmo. É uma operação que implica autoreferencialidade e a multidimensionalidade do ser e quando se manifesta, o sujeito tenta se ver como objeto de um conhecimento de si, um sujeito/objeto no meio de tantos outros sujeitos/objetos que necessitam emancipar-se, autoformar-se, para conquista de sua autonomia pessoal, intelectual e moral. 
Esta dimensão, assim como assinalada por Pineau, envolve aspectos existenciais extremamente significativos e importantes.

Por que estamos privilegiando esta dimensão? Porque além das outras terem sido mais bem exploradas, debatidas e estudadas pelos profissionais da área, a dimensão autoformadora traz consigo a questão existencial, a formação do SER DOCENTE que ultrapassa os aspectos educacionais e sociais da vida. Ela é também expressão de um processo de antropogênese, pois a autoformação transita entre a auto e a ontoformação e acabam se transformando numa totalidade indivisível. Ela implica em tornar-se sujeito. Em autonomizar-se como sujeito a partir de processos autoformadores. Não é apenas o Eu psicológico, o Eu social ou o Eu docente que está em jogo, mas o sujeito consciente de seus atos, consciente do imbricamento do seu SER com o seu FAZER que se transforma enquanto ele se auto-transforma.

Baseados também em Maturana e Varela (1995; 1997), podemos também perceber que todo processo de formação é sempre um processo de co-formação. Este termo evidencia o acoplamento estrutural em termos de energia, matéria e informação que circulam entre os sujeitos envolvidos, onde toda e qualquer ação formativo-formadora de um sobre o outro não deveria ser hierárquica, mas interativa e co-construída coletivamente. Pineau e Patrick (2005), ao falar sobre ecoformação, concorda com esta explicação.

\section{Transdisciplinaridade e formação docente}

Portanto, a formação docente, a partir da transdisciplinaridade, encontra nestes três eixos complementares - autoformação, heteroformação e ecoformação -, a sua unidade constitutiva, o seu núcleo principal, a representação de sua totalidade. É da dinâmica operacional entre esses elementos que nasce a complexidade constitutiva da ação docente formadora. Complexidade que se apresenta em todo processo de formação ao integrar e envolver a formação na relação consigo mesmo (autoformação), a formação na relação com o outro (heteroformação) e a formação com o meio ambiente (ecoformação). Esta complexidade se revela tanto em nível do sujeito multidimensional, como do técnico-pedagógico ou do sociocultural, níveis que representam a totalidade constitutiva de um sistema de formação docente.

A transdisciplinaridade requer, por outro lado, que a realidade docente seja também conceitualmente trabalhada a partir do pólo representativo dos níveis de realidade. Este pólo revela que tanto na Natureza como também em relação ao conhecimento da Natureza existem diferentes níveis de realidade aos quais correspondem diferentes níveis de percepção, segundo Nicolescu (2002). A passagem de um nível de realidade a outro se dá pelo conhecimento, 
o que implica o uso de enfoques epistemológicos e metodológicos que levem em consideração tanto a existência de uma realidade que possui diferentes níveis ou estágios de organização, quanto diferentes níveis de percepção para poder conhecê-la.

Segundo Basarab Nicolescu (2002), existem hoje, pelo menos, três níveis de realidade. A realidade macrofísica (da escala supra-atômica), a microfísica (escala subatômica) e a realidade virtual, todas elas como suporte às nossas experiências, representações, interpretações, descrições, imagens e formalizações matemáticas. Cada nível é regido por leis e regras diferentes. Como já foi dito anteriormente, cada nível de realidade corresponde a um nível de percepção por parte do sujeito observador e o seu nível de percepção é influenciado pelo seu nível de consciência.

A passagem de um nível de realidade a outro, mediante o conhecimento e sua lógica - a lógica do 3o incluído, dá-se a partir dos níveis de percepção e de consciência do sujeito transdisciplinar na sua relação com o objeto. É o seu nível de percepção que o leva a perceber a existência de uma outra possibilidade diferente das anteriormente apresentadas, a presença de um terceiro termo, onde as relações A e não-A coexistem e produzem uma terceira alternativa diferente das duas que lhes deu origem. Por exemplo, no nível de realidade macrofísico, as coisas são percebidas de modo separado, fragmentado e dual. A lógica que prevalece, portanto, é a dualidade, onde A é diferente de não-A e ambos estão separados. Aqui, prevalece a separabilidade, a fragmentação, a objetividade clássica e a simplificação. Conseqüentemente, trazendo isto para o campo social, trabalhamos em educação a partir de dados objetivos, concretos, observáveis e racionais. Aqui, as disciplinas pouco se comunicam. Cada uma tem sua lógica, sua linguagem, seus métodos e suas fronteiras separadas e impermeáveis. Traduz, portanto, uma realidade unidimensional, unidisciplinar, podendo até mesmo ser considerada multidisciplinar. Todavia, mesmo assim, a realidade ainda continua fundada na concepção de que os objetos reais são independentes dos sujeitos ou da maneira como se observa a realidade e se constrói o conhecimento.

Ora, no momento em que se reconhece a existência de um outro nível de realidade diferente do macrofísico, como por exemplo, o nível microfísico, onde a energia tem uma estrutura descontínua e se move por saltos, sem passar por pontos intermediários (NICOLESCU, 2002), percebe-se uma co-existência e uma complementaridade entre ambos. Então, o olhar tanto do físico como do docente começa a mudar e a perceber a existência de outras possibilidades anteriormente desconhecidas e que também podem ser aplicadas não só à experiência docente, mas às outras dimensões da natureza humana. Para tanto, é preciso reconhecer a existência da complexidade constitutiva da realidade, dinamizando todos esses processos a partir do conceito 
da não-separabilidade entre os diferentes níveis de realidade. Assim, a simplicidade da física clássica encontra o seu lado contraditório representado pela complexidade e nos informa que não existe divisão categórica entre o mundo físico e o biológico, entre o mundo da mente e o da consciência, ou entre a vida e a aprendizagem.

O importante, neste momento, é perceber que o que articula, liga e interliga os diferentes níveis de realidade é a complexidade da Natureza como fator constitutivo da dinâmica da vida. Ao mesmo tempo, é ela que também nos revela a ruptura da lógica clássica e a emergência de uma terceira possibilidade não prevista, chamada de 3 incluído, como foi dito anteriormente. Assim, a percepção e a vivência desses processos, mediante os quais se articula e se percebe a ligação existencial de dois ou mais níveis de realidade, acontece a partir da consciência de cada sujeito, de sua capacidade de percepção da tessitura comum (complexidade) que existe entre esses níveis e da convergência dos diferentes processos interagindo.

Assim, a lógica do $3^{\circ}$ incluído se manifesta e se explicita a partir da percepção do que acontece em um outro nível de realidade diferente do macrofísico, cuja dinâmica interativa acontece em função da complexidade constitutiva da realidade. Esta lógica revela a existência de outras possibilidades ainda não explicitadas.

Mas qual o tipo de formação docente que será capaz de promover a ampliação do nível de consciência dos nossos professores, no sentido de possibilitar a vivência de processos mais dinâmicos, integradores e transdisciplinares que transformam a nossa maneira de ser e de estar no mundo? Como trabalhar estes conceitos na prática docente e nos processos formadores? Primeiramente, é necessário criar espaços e condições para a ocorrência da auto, hetero e ecoformação, para a vivência de processos mais integrados e integradores de aprendizagem, processos que resgatem a inteireza, a autoreferencialidade e a multidimensionalidade do docente/aprendiz/formador. Isso requer processos de formação diferenciados e trabalhados a partir de metodologias transdisciplinares que levem o docente a transcender a dualidade presente no nível de realidade em que ele se encontra. Para tanto, ele necessita vivenciar processos que o levem a se reconectar consigo mesmo, com o outro e com o sagrado presente dentro de cada um de nós.

Significa que o docente transdisciplinar, formado a partir de vivências mais integradoras, percebe a vida e a mente como elementos constituintes de um único e mesmo processo de grande complexidade, ao mesmo tempo em que reconhece a existência dessa estrutura paradigmática sistêmica e complexa que está por trás dos eventos, fenômenos e processos, em constante vir-a-ser. Compreende que a dinâmica existente entre os níveis de realidade macrofísica e microfísica possibilita, na verdade, a emergência de uma terceira possibilidade 
anteriormente não percebida, ao ter o seu pensamento, a sua percepção e o seu estado de consciência presos num único nível de realidade.

Como docentes, aprendemos a interpretar o cotidiano da sala de aula a partir de um único e mesmo nível de realidade, o que certamente nos condicionou a ver o erro como algo negativo e não como fonte inesgotável de aprendizagem ou como uma etapa reveladora e importante do processo de construção do conhecimento. Ora, ao aprimorar seu nível de percepção e de consciência, o docente e o discente começam a perceber que foram os seus erros e acertos as maiores fontes de evolução em suas vidas e que o aprender dos próprios erros foi uma tarefa fundamental para que todo e qualquer profissional possa evoluir em sua área de trabalho. Mais do que ontem, é preciso tomar consciência a respeito da importância de se perder o medo de errar enquanto se aprende. Esta consciência implica um outro nível de percepção da problemática educacional e este entendimento é crucial para o crescimento profissional docente, devendo ser uma atitude com prazo de validade para toda a sua vida. Reconhecer o próprio erro, aprender a dialogar, a divertir-se e a crescer com ele, facilita o processo de aprendizagem individual e coletivo, e tornam ainda mais relevantes e significativos os processos de construção do conhecimento e de desenvolvimento humano.

Se o docente se encontra em um único e mesmo nível de realidade, seus erros e acertos serão vistos como polaridades opostas e, conseqüentemente, devem ser punidos com repreensões e notas baixas. Sua compreensão limitada do que seja o processo de construção do conhecimento nega-lhe a possibilidade de perceber que erros e acertos são duas faces de uma mesma moeda. Aquela que lhe abre as portas do conhecimento e da aprendizagem, e o portal da sabedoria e da evolução consciente, já que erros e acertos podem dialogar de maneira dinâmica e criativa, complementar e enriquecedora, dentro de cada um de nós.

Mas, para tanto, o professor precisa possuir uma mente mais aberta e evoluída, uma consciência transdisciplinar, para poder perceber a complexidade dos processos e o lado construtivo e criativo do erro e para melhor entender a dinâmica da realidade. É o diálogo construtivo entre erros e acertos que leva à emergência de outras possibilidades anteriormente não percebidas ou não valorizadas.

\section{Docência transdisciplinar e lógica ternária de formação}

Portanto, uma consciência transdisciplinar vai além da polaridade ou dualidade erro-acerto e interpreta a realidade a partir da existência de uma terceira via já não excludente, mas integradora em sua dinâmica, que o leva a 
perceber o outro lado que estava na ordem implicada e que se revela a partir de uma consciência transdisciplinar mais elaborada. É esta mesma consciência transdisciplinar, com sua dimensão inclusiva, construtiva e criativa, que nos ajuda a perceber que o erro, associado aos mecanismos geradores do acaso e das bifurcações, pode colaborar para a ocorrência de novas descobertas científicas e para evolução do pensamento humano.

Desta forma, o docente transdisciplinar será capaz de entender a dimensão dialógica do erro, como produto intrínseco à própria dinâmica da vida, como condição que acompanha todo e qualquer processo de desenvolvimento, de transformação e de evolução. É neste sentido que ele deverá ser mais bem explorado, potencializado de maneira construtiva mediante um tratamento mais adequado. Torre (2005) entende o erro como um fato natural que acompanha a aprendizagem, do mesmo modo que as crises e tensões impulsionam processos de desenvolvimento individual e social. Assim compreendido e trabalhado, ele se revela de uma outra forma, como sinalizador de uma etapa ou de um possível desajuste entre o esperado e o obtido, sem comportar qualquer atitude sancionadora ou punitiva. Passa a ser, portanto, um estímulo ao diálogo e à abertura, para que o estudante possa expressar seus pensamentos e sentimentos, suas dificuldades e potencialidades.

Assim, o docente transdisciplinar, ao trabalhar com esta compreensão a respeito da complexidade da realidade, transforma a pedagogia do erro em uma pedagogia do êxito (TORRE, 2005), da mesma forma em que nós transformamos nossos erros pessoais em vivências significativas e relevantes para a evolução de nossa consciência pessoal ou profissional.

Como é possível perceber, o enfoque transdisciplinar do conhecimento, cuja dinâmica compreensiva trafega por diferentes níveis de realidade, de percepção e de complexidade, pode também se transformar em um método que permite o reencontro da riqueza do sentido aparente com o sentido consciente que está implícito nas coisas, nos processos e nos fenômenos, algo que estava escondido, dobrado em si mesmo. É como se o sentido daquilo estivesse dentro de uma ordem implicada que se desdobra a partir dos diálogos que acontecem nos processos de construção do conhecimento. Portanto, é um novo sentido que se revela mediante uma prática vivenciada a partir de uma escuta sensível (BARBIER, 2004), de uma espera vigiada, como nos diria nossa amiga Ivani Fazenda.

Tudo isso nos revela que a docência transdisciplinar requer do educador uma atitude condizente com o seu grau de percepção e de consciência. Uma atitude de abertura que promove a alternância entre os diferentes processos que se complementam, entre sujeitos e seus saberes; entre os saberes do educador e do educando. É uma atitude inclusiva que aceita o inesperado e acolhe o imprevisível, que incentiva discussões saudáveis e a expressão dos 
diferentes pontos de vista, sejam eles científicos, filosóficos ou educacionais. Assim, o docente transdisciplinar tem uma percepção e uma consciência diferenciada. Ele não se sente dono da verdade, já que a transdisciplinaridade e a complexidade não combinam com uma única maneira de ver a realidade e de compreender o mundo.

O docente transdisciplinar é aquele que tenta, a partir de seus níveis de percepção e de consciência, potencializar, construir o conhecimento e acessar as informações que estão presentes nos outros níveis de realidade, mediante o reconhecimento da complexidade constitutiva da vida, que traz consigo uma visão mais unificadora e global de sua dinâmica e do funcionamento da realidade. É esta mesma compreensão que leva o professor transdisciplinar a reconhecer a dinâmica engendrada pela ação simultânea do que acontece nos níveis de realidade, percebendo mais facilmente a sincronicidade dos processos e as correspondências existentes entre o mundo interior do sujeito e o mundo exterior do objeto. Desta forma, para o docente transdisciplinar, fica mais fácil compreender que o conhecimento construído não é nem exterior e nem interior, mas tudo isso ao mesmo tempo; algo que é gerado por uma ação que é perceptivamente guiada em função do que acontece no exterior do sujeito, mas que, simultaneamente, implica uma cooperação global das diferentes dimensões constitutivas do ser humano (VARELA; THOMPSON; ROSCH, 1997).

É um conhecimento sincrônico e diacrônico em sua dinâmica autoeco-re-organizadora. Isto porque todo sistema auto-eco-re-organizador, assim como é o ser humano, implica uma conjunção ou uma convergência de dinâmicas sincrônicas e diacrônicas que levam à articulação das diferentes dimensões humanas na produção do conhecimento. O mesmo acontece com as práticas formadoras propostas por Gastón Pineau (2006), envolvendo o nível do sujeito (auto), representado pelo nível psicopedagógico, o nível hetero representado pelo outro, e o nível eco que traduz o pólo das influências do ambiente, das técnicas e das tecnologias nos processos de construção do conhecimento. Assim, a consciência transdisciplinar de Gastón Pineau distingue esses três níveis como sendo complementares em termos de análise das ações que intervém nos processos de formação dos sujeitos sociais.

Segundo Pineau (2006), a lógica ternária da formação vai além da lógica binária excludente que não considera a presença do terceiro incluído. Isso também nos leva a compreender, a partir de Maturana, que a formação docente acontece sempre na relação. Possui, portanto, uma natureza ecosistêmica (MORAES, 2004). Ou seja, ela acontece a partir das relações do sujeito consigo mesmo (auto), com o outro (hetero) e com as circunstâncias geradas pelo ambiente (eco). Ainda inspirados em Maturana e Varela, reconhecemos também que toda e qualquer formação acontece na relação do sujeito com o objeto e o que ocorre nas relações, querendo ou não, tem 
conseqüência em nossa corporeidade. Da mesma forma, o que acontece na corporeidade também apresenta conseqüências na formação dos sujeitos aprendentes. Em termos educacionais, esta compreensão é de extrema relevância.

Ela também nos revela que formação implica uma história de transformações recorrentes, onde todo e qualquer ato docente tem conseqüência naquilo em que nos tornamos, tanto como docente ou como pessoa comum (autoformação). Isto porque, segundo Maturana, o SER e o FAZER estão verdadeiramente imbricados em nossa corporeidade. E o que acontece no nosso corpo tem tudo a ver com as nossas ações e reflexões (MORAES, 2003).

\section{Tudo que forma, na realidade, transforma}

Daí a importância da frase de Maturana ao reconhecer que "nada do que fazemos jamais é trivial, porque somos um tempo presente em mudança" (MATURANA, 2000, p. 95). Esta frase confirma que, biologicamente falando, formação implica transformação e mudança, ratificando, assim, a nossa compreensão inicial de que tudo que forma, na realidade, transforma. Isso nos leva também a ratificar a proposta de formação ternária de Gastón Pineau (2006), onde autoformação implica autotransformação em co-existência com o outro (heteroformação) e com as circunstâncias vivenciadas (ecoformação). É, portanto, auto-eco-heteroformação, cuja dinâmica entre as três dimensões acontece de maneira simultânea.

Vale a pena ainda lembrar que o conceito de autopoiese de Maturana e Varela (1995) ratifica esta capacidade autoformadora e autotransformadora dos sistemas vivos, esta capacidade autoprodutora e autoconstrutora de si mesmo. Assim, todo processo de formação acontece a partir de uma dinâmica autopoiética e enativa, algo que ocorre de dentro para fora, mediante processos co-determinados que acontecem a partir do acoplamento estrutural entre o indivíduo e o meio onde está inserido (MATURANA; VARELA, 1995; VARELA; THOMPSON; ROSCH, 1997). Esta maneira de compreender os processos de construção do conhecimento desenvolvidos nos ambientes formativos revela a fragilidade e a inconsistência teórica do paradigma instrucionista.

\section{Identidade profissional e formação docente}

A partir deste referencial, todo e qualquer processo de formação docente, a partir da complexidade e da transdisciplinaridade, deve ser algo sempre aberto, vivo e criativo, desenvolvido em um espaço contínuo de reflexão, 
de autoformação, de abertura e aprimoramento humano/profissional. Não apenas no que se refere às tarefas relacionadas à sua atuação externa como docente, mas também em relação aos seus processos internos, auto-eco-heteroformadores e transformadores de sua própria natureza.

É mediante as vivências de processos autoformadores, acionados a partir do acoplamento estrutural que acontece entre os indivíduos e seus ambientes, que o docente constrói e aprimora sua identidade profissional, mediante um processo aberto de desenvolvimento integral. Segundo Antonio Medina (2001), entende-se por identidade profissional o processo de construção de conhecimento e desenvolvimento da docência, enfatizado pela busca constante dos valores e assimilação da cultura de formação. Sua identidade pode ser observada a partir de sua conduta, dos seus discursos ou do conjunto de percepções ou representações experimentado pelo docente no seu fazer didático-pedagógico. Sua identidade é um reflexo de seu processo evolutivo e de sua consciência.

Assim, a identidade docente, por sua vez, é construída de maneira crescente e recursiva mediante processos de auto-reflexão e de auto-organização constante, onde o produto é, ao mesmo tempo, causa e causante daquilo que produz. Biologicamente falando, não dá para separar desenvolvimento humano do desenvolvimento profissional, já que o SER e o FAZER estão absolutamente co-implicados na corporeidade humana. Para tanto, é preciso desenvolver uma atitude constante de buscas e melhorias comprometidas com o seu trabalho e com suas experiências educativas. Deste processo em aberto, desta espiral evolutiva, participam também outros sujeitos e representantes institucionais com os quais se vivencia uma cultura de colaboração e de co-responsabilidade no desenvolvimento das tarefas planejadas.

Desta forma, todo processo formativo implica uma dinâmica de natureza auto, hetero e eco-formadora aberta, fundada na solidariedade, no questionamento constante e nas reflexões sobre as ações desenvolvidas. Esta capacidade de questionar traz consigo a complexidade, a incerteza, a perplexidade, a emergência e a mudança, dimensões que requerem do profissional docente um compromisso maior, bem como uma responsabilidade mais acentuada, como decorrências de sua consciência transdisciplinar.

\section{Formação docente como ação perceptivamente guiada}

Sabemos que todo processo de formação docente depende do tipo de experiências vivenciadas nos ambientes de aprendizagem. Portanto, é um saber docente que depende da qualidade das vivências ocorridas em sua trajetória profissional, como também de uma realidade que, além de educacional, 
é também de natureza biológica, psicológica, cultural, política e social no seu sentido mais amplo. Isto indica que o saber docente depende, prioritariamente, do sabor das experiências desenvolvidas nos ambientes educacionais e que acontece pelo simples fato de se ter um corpo dotado de diversas capacidades sensório-motoras ativadas a partir de ações no contexto em que atua.

Apoiados em Varela, Thompson e Rosch (1997), podemos também afirmar que a ação docente é sempre uma ação perceptivamente guiada, isto é, algo que se desenvolve, a cada instante, a partir do que acontece nas estruturas sensório-motoras do sujeito vivente, a partir de sua percepção e capacidades construídas a todo instante, de acordo com o que acontece no ambiente de aprendizagem. Assim, o saber docente, embora dependente das estruturas internas do sujeito aprendente, não pode estar separado do que acontece no ambiente e do sabor de cada experiência desenvolvida, pois estão acoplados em termos de energia, matéria e informação que circulam no ambiente.

Esta compreensão facilita o nosso entendimento de que o SABER e o FAZER DOCENTES, "com sabor", acontecem a partir de processos em situações de co-deriva natural (MATURANA; VARELA, 1995). Tais situações têm muito mais a ver com processos de abertura e com um devir não previsto anteriormente, do que com um processo de natureza fechada e predeterminada. A atuação docente está muito mais próxima de um fluir em uma rede de configurações auto-eco-reguladoras, do que de um processo de ajuste a uma realidade educacional prévia, fixa e predeterminada.

Desta forma, o saber docente é parte integrante de um mundo que existe em comunhão e que é, ao mesmo tempo, aparentemente estável e mutante. Um mundo onde o docente e o ambiente de aprendizagem estão verdadeiramente co-implicados. Conseqüentemente, docente e discente evoluem juntos, revelando assim que o meu saber docente também evolui em comunhão com o saber e o sabor experiencial discente, vivenciando uma relação de interdependência docente/discente. Assim, a evolução do meu ser docente é sempre um processo em co-evolução, no qual eu só me realizo como tal na vivência experiencial com os meus alunos. Portanto, independente do nível em que ocorra e das pessoas envolvidas, nossa evolução, como profissionais da educação, nunca acontece de maneira individual, mas, sim, coletiva.

\section{Concluindo}

Para concluir, mesmo que provisoriamente, é preciso observar que a formação docente, tendo a complexidade e a transdisciplinaridade como dimensões epistemo-metodológicas, requer que a concebamos como um 
processo integral e integrador, inter e transdisciplinar, tendo, como pilares importantes de sua construção teórica, a complexidade, os níveis de realidade e a lógica do $3^{\circ}$ incluído.

$\mathrm{Na}$ realidade, esta mudança paradigmática na formação docente requerida pela complexidade e pela transdisciplinaridade leva-nos a perceber que todo processo de formação, independente do paradigma utilizado, sempre esteve, exclusiva e prioritariamente, voltado para os objetos do conhecimento e para o contexto educacional. Isso significa que, desde um processo de formação de natureza mais artesanal, até o de natureza socioconstrutivista mais recente, sempre se pensou a formação docente a partir dos objetos do conhecimento e das relações socioculturais. Ou seja, privilegiou-se muito mais as dimensões hetero e ecoformadora a partir dos conteúdos curriculares, das técnicas, das estratégias, das organizações, da qualidade crítica da formação, do desmascaramento de processos ideológicos ocultos na prática, bem como do uso mais competente das tecnologias digitais. Muito pouca atenção foi dada aos processos autoformadores implícitos nas relações do sujeito com o objeto do conhecimento.

A concepção dos modelos de formação sempre esteve vinculada aos marcos teóricos e epistemológicos de determinados paradigmas que, de um modo ou de outro, predominaram nos momentos sócio-históricos do conhecimento social. Mesmo hoje, a formação docente ainda continua prioritariamente enfocada nas dimensões hetero e ecoformadora e na preparação do professor autônomo, criativo e crítico, sendo esta expressão um chavão que se apresenta em todo e qualquer discurso relacionado ao processo de formação. Embora reconheçamos que tudo isto seja importante, sabemos que o processo de formação não implica, única e exclusivamente, a relação sujeito/objeto do conhecimento e os aspectos contextuais. Não é só isto. Precisamos também estar mais atentos aos processos internos, autoorganizadores e complexos, atentos às dimensões ontológicas do ser em sua realidade contextual, ao movimento de sua consciência em evolução. Isto porque a educação e o futuro das novas gerações dependem muito dela.

É isto que a complexidade e a transdisciplinaridade nos solicitam: que centremos também nossas atenções aos processos autoformadores, às transformações interiores do sujeito docente, às mudanças que acontecem a partir do acoplamento estrutural docente/discente que surge na prática cotidiana gerada a partir das interações ocorrentes. Urge que trabalhemos melhor esta dimensão, pois é por meio dela que o formador reconhecerá os seus processos internos, os seus símbolos pessoais e culturais, as suas emoções, os seus desejos e afetos e que muito influenciam a qualidade dos processos formadores e de seu trabalho profissional. 
É o cuidado com esta dimensão autoformadora que o ajudará a revelar sua sensibilidade, sua intuição, seu imaginário, sua vontade de realizar algo diferente, dimensões que ajudam o formador a penetrar na zona de nãoresistência, tanto sua como de seus alunos. Para Nicolescu (2002), esta é também conhecida como a zona do sagrado. É ali que o formador transdisciplinar penetra com toda sua percepção, sensibilidade, imaginação, intuição e consciência e se realiza como tal ao expandir os seus níveis de percepção e de consciência no sentido de compreender o que acontece em um outro nível de realidade docente/discente. A compreensão desses processos colabora para aceleração de seu processo humano-evolucionista.

Para penetrar no campo do sagrado, com sua intuição, sensibilidade e imaginação, o formador precisa saber articular e reconhecer a existência de outros tipos de conhecimento e de outras realidades, nos quais a racionalidade, simplificadora e fragmentadora do conhecimento, dificulta sua percepção e compreensão, dificultando a elaboração das devidas respostas. É dentro deste arcabouço conceitual que precisamos também repensar a formação docente. E, para tanto, é necessário competência teórica, clareza epistemológica e metodológica e uma consciência transdisciplinar para que possamos verdadeiramente responder, neste início de milênio, aos três grandes desafios apresentados por Edgar Morin (2000) e que estão relacionados:

- aos processos de construção, desconstrução e reconstrução do conhecimento humano;

- à formação de cidadãos e não apenas indivíduos;

- ao desenvolvimento da consciência, como condição fundamental para a sobrevivência da humanidade.

Sabemos que o nosso futuro sempre foi e sempre será fruto de uma construção social e política. Mais do que nunca, entre outros fatores importantes, ele depende da educação e da atuação docente. Assim, concordamos com Prigogine (1986) quando ele nos diz que: "não podemos predizer o futuro, mas podemos influir nele". E, como educadores, precisamos estar mais atentos ao que está acontecendo, não apenas com a escola, com o nosso país e com o mundo, mas também com tudo aquilo que está afetando a vida neste nosso belo Planeta Azul.

E, como humanidade, mesmo sabendo que estamos sujeitos ao indeterminismo, à espontaneidade, às emergências, sujeitos à ação do acaso em nossas vidas, é preciso antecipar-nos em relação às eventualidades e preparar-nos para as contingências futuras. Daí a nossa concordância com a frase de David Böhm (1991) ao lembrar que tanto o passado como o futuro são reflexos do presente que nele se desdobra. 


\section{Referências}

ARDORNO, J. Abordagem multirreferencial das situações educativas e formativas. In: BARBOSA, J. G. (Org.) . Multirreferencialidade nas ciências e na educação. São Carlos/SP: Editora da UFSCAR, 1998.

BARBIER, R. A pesquisa-ação. Brasília: Lỉber Livro, 2004. (Série Pesquisa em Educação v. 3).

BÖHM, D. Sobre el dialogo. Barcelona: kairós, 1991.

DEMO, P. O profissional do futuro. In: LINSIGEN, I. V. (Org.). Formação do engenheiro: desafios da atuação docente, tendências curriculares; questões contemporâneas da educação tecnológica. Florianópolis: UFSC, 1999.

MATURANA, H. Transdisciplinaridade e cognição. In: BASERAB, Nicolescu et al. Educação e transdisciplinaridade. Brasília: UNESCO, 2000.

.VARELA, F. A árvore do conhecimento. Campinas: Psy, 1995.

VARELA, F. De máquinas e seres vivos. Porto Alegre: Artes Médicas, 1997.

MEDINA, A. La formación del profesorado: modelos y prácticas formativas en el centro en el aula. In: SEPÚLVEDA, F.; RAJADELL, N. (Coord.). Didáctica general para psicopedagogos. Madrid: UNED, 2001.

O pensamento eco-sistêmico: educação, aprendizagem e cidadania no século XXI. Petrópolis: Vozes, 2004.

MORAES, M. C. Educar na biologia do amor e da solidariedade. Petrópolis: Vozes, 2003.

.; TORRE, S. DE LA. Sentipensar: fundamentos e estratégias para reencantar a educação. Petrópolis: Vozes, 2004.

MORIN, E. Ciência com consciência. Sintra: Europa-América, 1994.

Método 01: a natureza da natureza. Sintra: Europa-América, 1997.

Amor, poesia, sabedoria. Lisboa: Instituto Piaget, 1999.

Os sete saberes necessários à educação do futuro. São Paulo: Cortez, Brasilia: UNESCO, 2000.

NICOLESCU, B. etal. Educaçãoe transdisciplinaridadeII. Brasilia: UNESCO, 2002.

PINEAU, G.; PATRICK, P. Trandisciplinarité et formation. Paris: L`Harmattn, 2005. 
Investigaciones transdisciplinarias em formación. In: JORNADA DE INNOVACIÓN UNIVERSITÁRIA: TRANSDISCIPLINARIDAD, 2., Universidade de Barcelona, 2006, Anais... Barcelona, 2006.

PRIGOGINE, I. O reencantamento da natureza. In: WEBER, R. (Org.). Diálogos com cientistas e sábios: a busca da unidade perdida. São Paulo: Cultrix, 1986.

SHELDRAKE, R.; ABRAHAM, R.; MAKENNA, T. Caos, criatividade e o retorno ao sagrado: triálogos nas fronteiras do ocidente. São Paulo: Cultrix,1994.

SOMMERNAN, A. Formação e transdisciplinaridade: uma pesquisa sobre emergências formativas do CETRANS. Dissertação (Mestrado em Ciências da Educação) - Faculdade de Ciências e Tecnologia da Universidade de Nova Lisboa e à Université François Rabelais de Tours. Lisboa: 2003. Disponível em: $<$ http://www.redebrasileiradetransdisciplinaridade.net/mod/resource/ view.php?id=18>. Acesso em: 20 set. 2006.

TORRES, R. M. La profesion docente en la era de la informática y la lucha contra la pobreza. Santiago/Chile. UNESCO-OREALC, 2002. Disponível em: $<$ http://www.lpp-uerj.net/olped/Mec/biblioteca/docentes_tec.pdf $>$. Acesso em: 10 set. de 2006.

TORRE, S. DE LA; BARRIOS, O. Curso de formação de educadores: estratégias didáticas inovadoras. São Paulo: Madras, 2002.

Aprender de los errores. Buenos Aires: Magisterio de la Plata, 2005.

VARELA, F.; THOMPSON, E.; ROSCH, E. De cuerpo presente: las ciencias cognitivas y já experiencia humana. Barcelona: Gedisa, 1997. 